\title{
CREATIVE WARM-UPS AND TIME FILLERS FOR A SUCCESSFUL ENGLISH LANGUAGE CLASS
}

\author{
Klaudia Paulikova
}

doi: $10.18355 / P G .2018 .7 .1 .4$

\begin{abstract}
Applying creativity into foreign language teaching is becoming more and more important for teachers. Moreover starting lessons in the most appropriate possible ways is one of the key factors for a successful classroom. For this reason, using creative and innovative techniques and activities as warmers and time fillers can be beneficial not only for future teachers but also for the in-practice ones desiring to cheer their lessons up. The paper focuses on introducing warmer and time filler activities from a theoretical point of view, which is underlined by researching their benefits and overall influences on the teaching process.
\end{abstract}

\section{Key words}

creativity, warm-ups, time fillers, English teaching

\section{Introduction}

Teaching a foreign language most of the times requires not only high proficiency of language and good knowledge of methodology, but it many times also cries for some extra that could be provided in order to meet the criteria of a lesson to be called "successful." It is the teachers' creativity in the lessons, which helps the learners gain and retain motivation and assists in the development through their language studies. Good teachers, as Gajdacova Veselá and Kovácikova (2016) point out, are able to make any topic an interesting one when it comes to foreign language education, all depending merely on the way it is dealt with. Creativity at lessons can, as a result, be approached from various angles. Looking at it from the viewpoint of lesson starters and time fillers, however, it can be stated that it plays quite an important role in language education. There is a simple reason for that. Similarly, as all the first impressions in life are extremely important, so do the beginnings of lessons determine the overall success of the teaching process, especially in terms of catching attention or sustaining the interest of the learners.

\section{Warm-up activities and TIME fillers}

Being the very first thing the learners at the lesson do, a well-chosen and planned warm-up becomes the most essential piece for setting the tone of the upcoming minutes. Cotter (2014) explains that a fun warming activity not only creates a relaxed atmosphere with raising the levels of energy but also makes the learners switch into the "English mode," which apparently helps in detaching from the world outside the classroom, where English is not used. Zakhareuski (n.d.) adds that a good warmer can moreover prepare the learners for the topic of the lesson itself, which can introduce the upcoming 
structures, thus giving them an idea about what to expect. The same applies for time fillers. Either for filling up time when finished too early, or for loosening the lesson between two more straining exercises, time filling activities are a fantastic way for smoothing the transition periods, keeping the learners engaged and, last but not least, refilling them with the energy to go further (Cox, 2015).

The current day and age offer the teachers endless possibilities in choosing the most appropriate activities for starting off their lessons. It is completely up to their choice; whether they are going to opt for verbal, kinaesthetic, audial or visual activities, the most important factor is to make the class alive. Verbal warmer and time filler activities are an excellent way for practicing previously acquired language or grammatical structures (Spratt, 1994). Considering the great variety of learners and even greater variety of the existent learning styles, it becomes almost essential for considering audial, visual or kinaesthetic stimuli in the classroom just as much an as the verbal ones (Helgelsen, 2002).

Having a look into the context of audial activities, for instance, it becomes evident that they are most frequently used with younger learners. Ward (1980) remarks the numerous linguistic, psychological and social benefits these activities tend to bring forth, from teaching correct rhythm, stress, and intonation through motivation of learners up to the mutual cooperation they encourage. Thagard (2011) moreover adds that audial language stimulation, besides of creating a positive atmosphere in the classroom and allowing every student to participate, helps in reviewing previously acquired language and picking up new language much more easily. What is also important, however, is that all these great benefits are also applicable to the older learners if not with all age groups, as well. Activating specific parts of the brain and connecting up with the language centre, audial activities are found as an enhanced way for gaining, storing and then reusing pieces of information.

Visual input has greatest benefits for learners considered to be visual types of learners. These activities not only make the lessons themselves more attractive by adding shapes, colors and visual movements into the lessons, but also help the learners "see" the content they are learning (Stancampiano, 2013). They may contribute to easier learning and language understanding and ease the pressure of difficult tasks, such as working with literary or scientific texts (Yunus et al., 2013).

Kinaesthetic language input has recently been considered as one of the most powerful tools for successful language teaching. Looking at kinaesthetic activities from the viewpoint of the human brain, it becomes evident that language acquisition takes part in the left hemisphere, whereas physical movements make the right hemisphere involved, as well. This results in both hemispheres working at the same time, which is seen as a great advantage in not only energizing the students but also making them more willing to work (Promislow, 1999). Moreover, Helgelsen (2002) adds that by releasing endorphin and dopamine into the body while practicing physical movements the students get a bigger chance for understanding the patterns and learning the structures more easily than by omitting these. 
Drawing a sharp line between the kinds of activities is, however, almost completely impossible. Especially these days, when the world offers thousands of kinds of methods, approaches, techniques, and activities, which many times have the tendency to blend the kinds of input. It results in using, whether knowingly or unknowingly, techniques and activities offering multisensory input, which, as studies show, tends to be extremely popular and beneficial. Varnes (n.d.) explains the countless benefits of multisensory language learning in easier language acquisition, making the lessons more attractive, activating learners' brains and adding efficiency to the overall teaching process.

Whatever kind of activity a teacher chooses for the start of their lessons, it is vital that they think it over in advance and plan it well. The numerous benefits of these activities are subject to further investigation, which, in the following part of the article, gives supplementary details of how the warmups and time fillers work in real classroom conditions.

\section{Reseach}

The study used qualitative research based on investigating the importance of using warm-up and time filler activities. It involved researching a class of university students, whose level of English was ranging from level A2 to B1 of the Common European Framework of Reference. The respondents of the study were exposed to English classes once a week for ninety minutes through the course of a thirteen week semester. The study involved twentysix respondents, who were chosen according to convenience sampling.

The study was planned and conducted according to previously set objectives and research questions. The researcher's aims were:

1. to find out what benefits the warmers and time-fillers had on the lessons of English

2. to find out the reflections on the activities from the respondents

Based upon these, two research questions emerged:

1. What benefits do the warmer and time filler activities have for foreign language education?

2. What are the reflections of learners on the given activities?

\section{Activities}

There were four warmer, and four-time filler activities are chosen for the research. The warmers were applied at the very beginnings of the lessons and their duration ranged from five to ten minutes. The time filler activities were generally applied after a more difficult task (working with a text, working with new vocabulary, writing task) and their duration was also ranging from five to ten minutes.

The four warmer activities were chosen and planned in accordance with the lesson plan for every lesson they were used at. The first activity was a verbal gap-filling activity. The learners were handed papers with a short text, which included the vocabulary practiced on the previous lesson. The learners' task was to fill the missing words into the text according to their own choice with the aim of making the text as creative and funny as possible. 
The second warm-up was a kinaesthetic brain gym exercise. The learners were asked to work in groups of four. Each of the members of the group was labeled with the numbers one to four. They were asked to count from one to four, making sure those learners spoke up, who correlated with the number. After a few rounds, they were asked to replace saying "one" with a clap of a hand. After another few rounds they were asked to replace "three" with a snap of the fingers, then "four" with a stump of the foot and finally "two" with a hit into the table.

The third activity was a visual activity. The learners were shown a situational picture, which was corresponding to the topic of the given lesson, but the learners did not know about it. The learners were asked to form groups of three and discuss the picture. They were asked to focus on the background story of the situation, on the possible outcomes and the items present in it. After the group discussion, they were asked to compare their findings with the rest of the class. At the very end of the activity, they were explained the real situation with all the information necessary for moving forward.

The very last warm-up was an audio-visual activity, which included listening to a song and competing for winning most of the heard words. The learners were told to form groups of three and were dictated a set of words, which were written on separate straps of paper. The words were then placed in front of the groups, and a song was played. The task of the learners was to listen to the words in the song which they had previously written down. As soon as they heard a particular word, they were supposed to pick it up as fast as possible to win it. The winner of the competition was the one who had most words.

The time filler activities were also chosen and planned in accordance with the topic of each of the lessons. The first time filler was an alphabet game. The learners were asked to work in pairs and write down words for all the letters of the alphabet on a given topic under a specified time limit.

As the second time filler, the learners played a word chain game as a whole class activity. They were supposed to keep the word chain by saying words beginning with the last letter of the previous words. The student not able to say a word in five seconds was out of the game.

Another time filler applied was a role-play. The learners were distributed role-cards with their tasks on them and asked to perform their roles in groups by preparing the role-play. When they were ready, they performed in front of the class. The class then evaluated the performances and chose the wittiest and funny one as the winner.

Finally, the fourth time filler was a whole class activity. The learners were supposed to create a story by adding up sentences one by one. The first sentence of the story was given in advance, and they were asked to follow one rule - stick to the previously specified topic.

\section{Methods}

Based on the nature of the research, there were two methods chosen for investigation - observation, and questionnaire. The observation was conducted on eight lessons, and it focused on the phenomenon of using warmer and time filler activities throughout the lessons and their benefit for 
learning languages and overall success of the lessons. The observation was happening simultaneously with the lessons, and the received information were recorded by the researcher after the lessons. There were four lessons observed where warmer and time filler activities were not used and four lessons where the activities were used. The main fields of observation were the willingness of the learners to cooperate, their levels of energy for fulfilling tasks, concentration and overall atmosphere at the lessons. The collected data were analyzed, compared and processed for obtaining the results.

The questionnaire was afterward handed to all the respondents with ten items based on the research questions. Its main objective was finding out what reflections the respondents had on using the warm-up and time filler activities with regard to their personal viewpoints, opinions, and feelings about the investigated topic. The questionnaire was created by the researcher herself and was a non-standardized one, adapted in order to meet the criteria set in the planning phase of research. The items of the questionnaire were divided into three subsections. The first subsection focused on the lessons where warm-up and time filler activities were not used. Its aim was to discover how the learners perceived the lessons and themselves at the lessons. Moreover, it aimed at finding out how enjoyable and manifold the learners found those lessons. The second subsection was centered at the lessons where warmer and time filler activities were used. The respondents were asked to describe their feelings and impressions with regard to the activities and their overall willingness to cooperate. The last subsection asked the respondents to express their standpoints towards the possible benefits/deficiencies of using warmers and time fillers. They were also asked to make a general comparison between lessons where creative warm-ups and time fillers were used as opposed to those where such activities were absent.

\section{Reseach Results}

After the evaluation of the collected data, the information was processed into results. The following part examines the outcomes gained via observation of the researcher and the questionnaire administered to twenty-six respondents.

\section{Results of observation}

Based on the four main fields of investigation, it was found out that the warmer and time filler activities used throughout the course of the study were found rather enjoyable by the learners. Considering the overall atmosphere at the lessons, it must be stated that the lessons with these activities appeared more relaxed and filled with positive energy. Comparing them to the lessons where warmers and time fillers were not used, the overall interest in the subject matter itself was raised, as well. Due to the fact that both the warmers and time fillers were connected to the topic of learning, the students got more drawn into the happenings in the classroom, performed better and enjoyed it more.

That was interconnected with their willingness to cooperate, as well. They were performing the activities with joy and interest, and as the activities were set to be enjoyable and competitive, the learners were eager to fulfill all the 
given tasks. Their willingness to fulfill more difficult tasks (before and after these activities) was also raised.

Even though it cannot be stated that the learners' concentration was higher on the lessons where warmers and time fillers were used, it became evident that after performing the warm-up activities the learners got more energized and refreshed. Considering the levels of energy, as the last field of investigation, it became evident that the warm-up activities were found very refreshing and energizing as the lessons took place in the early mornings. The activities for filling time while lessons were ongoing were also found very beneficial. They not only helped the learners release the excessive levels of energy but also reactivated their interest in the lessons. Thanks to the filler activities, which were applied around the halftime of the lessons, the learners did not become dull or bored, as they did on those lessons where creative activities were not used at all. Due to the fact that the learners were working in pairs or small groups they were enjoying the activities very much.

\section{Results of the questionnaire}

The analysis of the results of questionnaires was categorized according to the three main subsections of the questionnaires: lessons without using warmers and time fillers, lessons with time fillers and warmers and the learners' standpoints towards the possible benefits and deficiencies on using these activities.

\section{Lessons without warmers and time fillers}

The results of the first category showed that the vast majority of the respondents reflected the lessons without using warmers and time fillers as average and ordinary. They claimed that they could not find any difference between those lessons and any other lessons or subjects they attended. However, they added that it was very hard for them to find motivation and will for working at the very beginnings of the lessons, as they were taking place in the early mornings.

\section{Lessons with warmers and time fillers}

To the second subsection, which focused on lessons where time fillers and warm-ups were used, the respondents collectively reacted that the use of creative warmer activities was very important and beneficial for the overall success of the lessons of their foreign language studies. One of the respondents also commented that:

"As we are starting the lessons very early in the mornings, these activities always wake and cheer us up. Even if we did not start so early, they still would be very beneficial, because they are a pleasant and playful way how to get us, the students involved in the subject. And I am sure that also thanks to these we are improving. Moreover, they help us develop creativity and thinking skills."

The respondents also noted that the warmer and time filler activities influenced their ability in expressing themselves more clearly and speeding up the process of learning. Moreover, they mentioned that the activities 
released their stress, thus helped them in concentration, which resulted in better performances.

For the importance of using extra time filler activities throughout the course of the lesson all the respondents collectively agreed that they were extremely important and advantageous for various reasons. One of the main reasons, as they stated, was that the activities helped them refill their bodies and minds with energy, which was necessary for being able to move further in the lessons. Another reason was making the lessons more relaxed and enjoyable. One of the respondents supported this by their statement:

"It is very important for me to be able to release stress while studying hard, especially by doing some activities, which are funny and relaxing."

\section{Benefits and deficiencies of warm-ups and time fillers}

The very last subsection was centered at the standpoints of the respondents towards the benefits and deficiencies of using warmers and time fillers. As a result of the questionnaire, it can be stated that all the respondents had very positive reflections on the used activities. None of them remarked any deficiencies for using neither warm-up nor time filler activities. There were, however, many benefits that were highlighted.

The respondents noted that they found the activities very helpful and beneficial for their disburdening nature. They moreover added that these activities not only helped in building good relationships between the students but also had positive effects on the mutual relationships between the learners and the teacher:

"These activities build bridges between the teachers and their students, as the students feel the interest and the caring of their lecturer. It is not only about plainly explaining the new things to be learned, but also about caring to make the lessons interesting and enjoyable."

The respondents also saw a great advantage in refilling themselves with energy. The noted that after warm-ups and time fillers they felt more energized and ready for the upcoming tasks. Another advantage that was mentioned was creating a positive atmosphere for the lessons. The respondents claimed to feel more relaxed and fearless due to the humorous and pleasant nature of the performed activities. One of the learners added:

"I was very scared of speaking in English at first, but I think it is getting better. These lessons help me to improve."

Another great benefit noted by the respondents was the fact that the warmers and time fillers often offered a funny and playful way for practicing the target language. They remarked that even though they felt that the nature of those activities was relaxing, they did not stop working and using the language, which was very important for them.

Last, but not least, the respondents mentioned that because of the very early hour of their lesson they often felt extremely tired and unprepared to perform in a different language. The warm-ups, as they stated, helped them to switch their thinking in the target language on and get drawn into the happenings. 


\section{Conclusion}

The results of the study do not only work as a very positive feedback to the information depicted in the introductory part of the paper but also offer background information for numerous English teachers on how important and beneficial using warm-ups and time fillers on the lessons is. These findings may serve as guidelines for teachers when considering the application of such activities on their lessons with the possible outcomes and results they may achieve. In case that the teachers opt for applying warm-ups and time fillers and devote enough energy and time for preparing them well, their lessons of English will most possibly become filled with relaxed and positive atmosphere, which, naturally, is going to affect the students and the overall process of teaching, as well. The students might get more drawn into the happenings in the classroom, which can result in longer attention and better concentration. In addition to these, the overall performance at the lessons may be enhanced, as well. This may result in the students raising the levels of motivation, which can encourage them to study harder and more. The overall positive atmosphere created by these kinds of activities can improve the learning conditions and contribute to achieving overall success throughout the course of teaching and learning process.

\section{Bibliographic references}

COTTER, C. 2014. The Importance of Warming Up Students [online]. 2014.

[cit.

2017-20-11].

Available

online:

https://www.linkedin.com/pulse/20140917080559-26665973-the-importanceof-warming-up-students

COX, J. 2017. Classroom Activities: Teacher-Tested Time Fillers [online].

2017. [cit. 2017-20-11]. Available online:

https://www.thoughtco.com/classroom-activities-teacher-tested-time-fillers-

2081438

GAJDACOVA VESELA, K. - KOVACIKOVA, E. 2016. Zaklady didaktiky cudzich jazykov. $1^{\text {st }}$ ed. PF UKF v Nitre, 2016. 148 p. ISBN 978-80-5581050-8

HELGELSEN, M., 2002. Let's get physical- Warm-up activities involving movement and language [online]. 2002. [cit. 2017-17-11]. Available online: http://www.mgu.ac.jp/ ic/helgesen/physical/physical_-prehtml.htm

PROMISLOW, S., 1999. Making the brain/body connection. 1st ed. Kinetic Publishing Corporation, West Vancouver, 1999. 188 p. ISBN 9780968106631

SPRATT, M. 1994. English for the Teacher. $1^{\text {st }}$ ed. University Press, Cambridge, 1994. 158 p. ISBN 0-521-42676-6

STANCAMPIANO, J. 2013. The Benefits of Visual Facilitation in the Classroom [online]. 2013. [cit. 2017-26-11]. Available online: https://www.trainingindustry.com/articles/content-development/the-benefitsof-visual-facilitation-in-the-classroom/

THAGARD, D. 2011. Why should songs be used MORE in the Young Learners classroom? [online]. 2011. [cit. 2017-13-11]. Available online: 
https://oupeltglobalblog.com/2011/05/11/why-should-songs-be-used-morein-the-young-learners-classroom/

VARNES, D. n.d. How to Add Excitement to Your EFL Activities: Multisensory Learning online]. n.d. [cit. 2017-17-11]. Available online: https://www.fluentu.com/blog/educator-english/esl-efl-learning-activitiesmultisensory/

WARD, S. 1980. Dippitydoo. $1^{\text {st }}$ ed. Longman Group Ltd, London, 1980. 48 p. ISBN 0-582-51004-X

YUNUS, M., M. et al., 2013. Using Visual Aids as a Motivational Tool in Enhancing Students' Interest in Reading Literary Texts [online]. 2013. [cit. 2017-21-11]. Available online: https://arxiv.org/ftp/arxiv/papers/1305/1305.6360.pdf ZAKHAREUSKI, A. n.d. Why You Should Always Start With a Warmer [online]. n.d. [cit. 2017-14-11]. Available online: http://busyteacher.org/7610-why-you-should-always-start-with-awarmer.html

Mgr. Klaudia Pauliková

Constantine the Philosopher University in Nitra, Faculty of Education

Drážovská cesta 4, 94974 Nitra

Slovakia

klaudia.paulikova@ukf.sk 